\title{
SINAIS COPULATÓRIOS NO EXOESQUELETO DE UCIDES CORDATUS (LINNAEUS, 1763) (BRACHYURA: OCYPODIDAE): RELAÇÃO COM O SEXO E TAMANHO
}

\author{
João, M.C.A. ${ }^{1,}$; 'Mulati, A.L.L. ${ }^{1}$; \& Pinheiro, M.A.A. ${ }^{1}$ \\ ${ }^{1}$ Universidade Estadual Paulista (UNESP), Instituto de Ciências Biológicas (IB), Campus do Litoral Paulista (CLP), \\ Laboratório de Biologia da Conservação de Crustáceos (LBC/CRUSTA), São Vicente (SP). \\ *Autor correspondente: marcio.camargo96@gmail.com
}

Ucides cordatus (Linnaeus, 1763) é um caranguejo endêmico e de relevância socioambiental em manguezais. Sua cópula ocorre em intermuda, em seguida a muda nupcial, mas ainda faltam informações sobre a duração deste comportamento, entre outras. Alguns braquiúros apresentam sinais copulatórios no exoesqueleto, seja por abrasão entre os parceiros ou do exoesqueleto com o substrato onde vivem. Aqui foi avaliada esta possibilidade para U. cordatus, seja quanto ao tamanho dos exemplares, posição dos sinais no corpo e quantidade de sua ocorrência em cada sexo. Os exemplares foram capturados nos manguezais da ESEC Juréia-Itatins, SP (JUR) e PARNA Superagui, PR (SUP). Em laboratório foram sexados e medidos (LC, largura cefalotorácica, com um paquímetro 0,05mm). Foram inspecionados 1.294 animais (JUR: $n=651$; SUP: $n=733)$, dos quais 25\% ( $=323$ ) apresentaram sinais de abrasão copulatória (JUR: $n=200$, sendo 147 machos e 53 fêmeas; e SUP: $n=123$, com 42 machos e 81 fêmeas). Nas duas áreas os machos foram maiores do que as fêmeas (JUR: $t=8,23$; SUP, $\mathrm{t}=4,13$, ambas $\mathrm{p}<0,01$ ), com tamanho médio (LC) variando de 70,4-59,9mm e 68,7-63,4mm, respectivamente. Os sinais copulatórios ocorreram apenas na face externa do abdome, sendo no $3^{\circ}$ somito dos machos (JUR: 100\%; e SUP: 76,9\%) e no $4^{\circ}$ somito das fêmeas (JUR: 57,9\%; e SUP: 60,4\%). Nas duas áreas os machos apresentaram somente um único sinal por indivíduo (lado esquerdo ou direito), enquanto nas fêmeas foram verificados sinais duplos (lado direito e esquerdo). Em JUR os sinais copulatórios nos machos ocorreram com 70-75 mm LC, pouco superior ao dos machos em SUP (65-70 mm LC). No caso das fêmeas, aquelas com sinais possuíam tamanhos pouco inferiores ao dos machos (JUR: 60-65mm; e SUP: 55-60mm), mas similares entre si. Nos casais de braquiúros em cópula é comum que os machos apresentem maior porte do que as fêmeas, garantindo maior sucesso copulatório, fato confirmado nesta espécie utilizando a informação do tamanho de animais com sinal copulatório. O maior número de sinais no abdome das fêmeas pode ser explicado por sua posição externa quando em cópula, por abrasão com o sedimento pelos movimentos vibratórios promovidos pelo macho durante o bombeamento dos gametas. Estas informações podem auxiliar em discussões sobre o comportamento reprodutivo da espécie, embasar estimativas de tamanho de maturidade e auxiliar na delimitação da época de cópula, quando da existência de dados temporais de registro destes sinais.

Palavras-chave: caranguejo-uçá, cópula, Ocypodidae, reprodução.

Financiamento: FAPESP/FGB Projeto Uçá-Clima, Proc. n²014/50438-5; Bolsa IC - MCAJ, Proc. n 2017/22770-3; Bolsa IC - CERP, Proc. nº 2017/03915-0). 